\title{
POLÍTICAS PÚBLICAS DE FORMAÇÃO DE PROFESSORES DA EDUCAÇÃO BÁSICA: PANORAMA DAS ATIVIDADES EXTRACLASSE NO ALTO JEQUITINHONHA/MG
}

\author{
POLÍTICAS PÚBLICAS DE FORMACIÓN DEL PROFESORADO DE EDUCACIÓN \\ BÁSICA: DESCRIPCIÓN GENERAL DE LAS ACTIVIDADES EXTRACLASE EN \\ ALTO JEQUITINHONHA/MG
}

PUBLIC POLICIES FOR THE TRAINING OF BASIC EDUCATION TEACHERS:
OVERVIEW OF EXTRACLASSE ACTIVITIES IN ALTO JEQUITINHONHA/MG

Ednéia dos Santos Cunha NEVES ${ }^{1}$

Mara Lúcia RAMALHO ${ }^{2}$

RESUMO: Este artigo tem como objetivo apresentar os resultados da pesquisa que versam a respeito das Atividades Extraclasse (AEC), uma estratégia de formação continuada de professores da Educação Básica. As AEC, também denominadas na rede de ensino mineira como "Módulo II", são de caráter obrigatório, e compete aos gestores institucionais seu acompanhamento e monitoramento. Neste estudo, tomam-se como fundamentação teórica autores que dialogam com o universo da Educação, sobretudo, concepções da formação de professores com Pimenta (2005), Gatti (2008), Libâneo (2002) dentre outros. Como pressuposto metodológico optou-se pela pesquisa documental, a abordagem de caráter qualitativo e a técnica de análise de conteúdo. Este estudo teve como marco temporal o período 2013-2018 e o universo da pesquisa a microrregião da regional Diamantina, localizada no território do Alto Jequitinhonha, Minas Gerais. A pesquisa revelou que há cumprimento da frequência dos professores nas atividades previstas pelo processo de formação, objeto do estudo em questão, o que não pode ser entendido como garantia de reflexão sobre a ação, a qual se constitui a essência das AEC.

PALAVRAS-CHAVE: Formação de professores. Educação básica. Atividades extraclasse.

RESUMEN: El artículo tiene como objetivo presentar los resultados de la investigación sobre Actividades Extraclase (AEC), una estrategia de formación continua para docentes de la educación básica. Los AEC, también referidos en el sistema educativo de Minas Gerais como "Módulo II", son obligatorios y los gerentes institucionales son responsables de acompañarlos y monitorearlos. En este estudio, los autores que dialogan con el universo de la educación se toman como base teórica, sobre todo, concepciones de la formación docente con Pimenta (2005), Gatti (2008), Libâneo (2002) entre otros. Como supuesto metodológico se eligió como método la investigación documental, el enfoque cualitativo y la técnica de

1 Secretaria de Estado de Educação de Minas Gerais (SEE/MG), Diamantina - MG - Brasil. Diretora Educacional na Superintendência Regional de Ensino. Mestrado em Educação (UFVJM). ORCID: https://orcid.org/0000-0003-3100-5085. E-mail: edneia.neves@educacao.mg.gov.br

${ }^{2}$ Universidade Federal dos Vales do Jequitinhonha e Mucuri (UFVJM), Diamantina - MG - Brasil. Professora da Diretoria de Educação Aberta e a Distância e do Programa de Pós-Graduação em Educação. Doutorado em Educação (PUC/MG). ORCID: https://orcid.org/0000-0002-8314-4688. E-mail: mararamalho03@yahoo.com.br 
análisis de contenido. Este estudio se basó en el periodo 2013-2018 y el universo de investigación en la micro región de la regional Diamantina, ubicada en el territorio del Alto Jequitinhonha. La investigación reveló que existe un cumplimiento de la frecuencia de los docentes en las actividades previstas por el proceso de formación, objeto del estudio en cuestión, lo que no puede entenderse como garantía de reflexión sobre la acción, que constituye la esencia de la AEC.

PALABRAS CLAVE: Formación del profesorado. Educación básica. Actividades extraclase.

ABSTRACT: The article in question aims to present the results of the research on Extraclass Activities (AEC), a strategy of continuing education for teachers of basic education. The AEC, also referred to in the Minas Gerais education network as "Module II", are mandatory and institutional managers are responsible for monitoring and monitoring them. In this study, authors who dialogue with the universe of education are taken as theoretical basis, above all, conceptions of teacher training with Pimenta (2005), Gatti (2008), Libâneo (2002) among others. As a methodological assumption, documental research was chosen as a method, the qualitative approach and the content analysis technique. This study was based on the 20132018 period and the universe of research in the micro region of the regional Diamantina, located in the Alto Jequitinhonha territory. The research revealed that there is compliance with the frequency of teachers in the activities provided for by the training process, object of the study in question, which cannot be understood as a guarantee of reflection on the action, which constitutes the essence of the AEC.

KEYWORDS: Teacher education. Basic education. Extracurricular activities.

\section{Introdução}

O artigo apresenta como temática para discussão um recorte da pesquisa desenvolvida para obtenção do título de mestre no programa de Pós-Graduação em Educação da Universidade Federal dos Vales do Jequitinhonha e Mucuri (UFVJM), intitulada “A formação continuada do professor no contexto das políticas públicas de Educação Básica: uma análise das Atividades Extraclasse no Alto Jequitinhonha/MG". Tem como objetivo apresentar os resultados da pesquisa que versa sobre as Atividades Extraclasse (AEC), uma estratégia de formação continuada de professores da educação básica.

O texto encontra-se respaldado do ponto de vista científico em um arcabouço metodológico, utilizado por ocasião do desenvolvimento da pesquisa de mestrado da qual se origina, o qual se serviu dos princípios da pesquisa documental, um método para materialização dos dados, e a abordagem de caráter qualitativo, tendo como técnica a análise de conteúdo. Assim, as AEC no presente estudo serão abordadas como uma estratégia de formação continuada de professores em serviço, na Educação Básica. 
Quanto ao referencial teórico o estudo se ampara em pressupostos advindos de marcos constitucionais e infraconstitucionais que orientam e normatizam a prática das AEC em todo território nacional, flexibilizando para a construção de normativas em consonância com as demandas estaduais, que se consolidam em bases legais oriundas das Secretarias Estaduais de Educação (SEE). Em especial, a legislação que se consolida no Ofício Circular SEEMG No 2663/2016, o qual apresenta diretrizes para a operacionalização das AEC em MG.

No que se refere à formação de professores, o estudo se fundamenta em autores como Libâneo (2002), Gatti (2008) e Pimenta e Ghedin (2005), tendo em vista que eles trabalham com uma abordagem que contempla discussões relativas à melhoria da qualidade da educação, relacionando a temática diretamente com o processo formativo dos professores e articulando o assunto ao pensamento de Libâneo (2002, p. 64), quando menciona que "a formação geral de qualidade dos alunos depende da formação de qualidade dos professores".

De acordo com Cury (2008), o termo Educação Básica, presumida na Constituição Federal de 1988, compreende fundação, pedestal, que avança. Declarada direito de todos, merece da sociedade consideração de oferta qualificada no atendimento às suas etapas: educação infantil, raiz do processo; ensino fundamental, seu tronco; e ensino médio, sua finalização.

Quanto às Atividades Extraclasse, os documentos normativos: Lei do PSNP 11.738/2008, Decreto Estadual 46.125/2013 e Ofício Circular GS 2663/16 caracterizam-nas como importante instrumento da política pública de formação continuada, contribuindo para a melhoria da qualidade do ensino e para o princípio da valorização do magistério. As horas destinadas à prática das AEC são dedicadas a ações de capacitação, formação continuada, planejamento e outras específicas do cargo, exceto o exercício da docência. Tais atividades objetivam o crescimento profissional da equipe e o desenvolvimento das ações articuladas e coletivas, visando à implementação do Projeto Político Pedagógico (PPP) (BRASIL, 2008; MINAS GERAIS, 2013; SEEMG, 2016).

Assim, em consonância com tais pressupostos, são apresentados os resultados da pesquisa, cujo desenvolvimento foi motivado pela percepção de forma empírica da hipótese de que as orientações previstas na legislação vigente, que abordam as AEC desenvolvidas nas escolas estaduais pertencentes à Superintendência Regional de Ensino Diamantina (SRE), ainda não contemplam o esperado, restringindo o processo da melhoria da qualidade da educação no Vale do Jequitinhonha.

Dessa forma, vale ressaltar que o estudo do qual trata este artigo foi desenvolvimento na microrregião localizada no noroeste do estado de Minas Gerais, banhada pelo Rio 
Jequitinhonha, a qual possui necessidades constantes de investimentos e assistência, sobretudo no campo social, com carência de investimentos públicos e privados. É o quinto território com desenvolvimento menos populoso de Minas Gerais $\left(14,46 \mathrm{ha} / \mathrm{km}^{2}\right)$, com $60,33 \%$ da população em área urbana (184.386 habitantes) e 39,67\% em área rural (121.230 habitantes).

De acordo com Silveira (2018), a palavra território vem do latim "territorium", referindo-se a uma terra delimitada ou sob uma dada jurisdição. Ao longo do tempo os territórios são construídos ou descontruídos conforme modificações estruturais, políticas e econômicas pela sociedade, fortalecendo o sucesso ou não da região, de modo a caracterizar sua identidade.

Dessa forma, pode-se sintetizar a partir dos pressupostos de Servilha (2008), quando menciona que o "Vale do Jequitinhonha são muitos, tantos quantos são os diferentes olhares de seus diferentes atores sociais; tantos quantos somos nós em busca de resposta", que se materializam no olhar da pesquisadora para os municípios de Diamantina, Serro e Turmalina. Uma tríade que revelou diferentes nuances por meio da análise de prática das AEC.

\section{Políticas públicas de formação de professores da Educação Básica: do nacional ao regional}

Este artigo apresenta um diálogo do pesquisador com os pressupostos educacionais, contextualizando o leitor a respeito dos pilares estruturantes desta pesquisa, tendo para o diálogo embasamentos teóricos de autores clássicos e contemporâneos e de documentos infraconstitucionais que circulam no contexto nacional e regional.

Tais pressupostos fundamentam o olhar do pesquisador para o objeto em discussão, tendo em vista o processo formativo que se deseja apresentar, a saber: discussões referentes à Formação do professor, Educação Básica e Atividades extraclasse, pressupostos metodológicos e resultados obtidos.

No atual contexto brasileiro, a política pública educacional desenhada em bases legais pelo Ministério da Educação (MEC) se estrutura em eixos estabelecidos, em especial, no Plano Nacional de Educação (PNE). A Lei 13.005/2014 do atual PNE enfatiza nas metas 15 a 18 estratégias de formação inicial e continuada para os eixos da formação de professores, valorização dos profissionais e planos de carreira da educação, como suporte para uma educação de qualidade. Tendo em vista que esta pesquisa aborda a formação continuada do professor, evidenciam-se as seguintes metas: 
Meta 15: Garantir, em regime de colaboração entre a União, os Estados, o Distrito Federal e os Municípios, no prazo de 1 ano de vigência deste PNE, política nacional de formação dos profissionais da educação de que tratam os incisos I, II e III do caput do art. 61 da Lei ${ }^{\circ}$ 9.394, de 20 de dezembro de 1996, assegurado que todos os professores e as professoras da educação básica possuam formação específica de nível superior, obtida em curso de licenciatura na área de conhecimento em que atuam.

Meta 16: Formar, em nível de pós-graduação, 50\% dos professores da Educação Básica, até o último ano de vigência deste PNE, e garantir a todos os(as) profissionais da Educação Básica formação continuada em sua área de atuação, considerando as necessidades, demandas e contextualizações dos sistemas de ensino. Meta 17: Valorizar os (as) profissionais do magistério das redes públicas da Educação Básica, a fim de equiparar o rendimento médio dos (as) demais profissionais com escolaridade equivalente, até o final do $6^{\circ}$ ano da vigência deste PNE.

Meta 18: Assegurar, no prazo de 2 anos, a existência de planos de Carreira para os(as) profissionais da Educação Básica e Superior pública de todos os sistemas de ensino e, para o plano de Carreira dos(as) profissionais da Educação Básica pública, tomar como referência o piso salarial nacional profissional, definido em lei federal, nos termos do inciso VIII do art. 206 da Constituição Federal (BRASIL, 2014).

Nessa perspectiva, em 2017, o Ministério da Educação (MEC) define a formação dos professores da seguinte maneira: “A boa formação de professores é fundamental e tem um impacto direto dentro da sala de aula, principalmente, na questão da qualidade do ensino e do aprendizado das crianças e jovens nas escolas de Educação Básica do Brasil” (MEC, 2017). Levanta, ainda, os seguintes dados: desempenho insuficiente dos estudantes, baixa qualidade da formação inicial dos professores, currículos extensos com ausência de atividades práticas, estágios curriculares sem planejamento e sem vinculação com as escolas.

O diagnóstico realizado pelo MEC considera índices como o Censo da Educação, divulgado em 2016, demonstrando que dos 2.196.397 professores da Educação Básica no país mais de 480 mil só possuem Ensino Médio. e mais de 6 mil, apenas o Ensino Fundamental. Aproximadamente 95 mil têm formação superior, sem cursos de licenciatura. Apenas 1.606.889 possuem formação em licenciatura, porém, muitos desses não atuam em sua respectiva área de formação (MEC, 2017).

A Coordenação de Aperfeiçoamento de Pessoal do Ensino Superior (CAPES) realizou, em 2017, levantamento de indicadores de adequação da formação docente nos níveis da Educação Básica por disciplina no Brasil, organizando-os em 5 grupos de percentual de disciplina ministradas por professores, a saber: 1- Com formação superior de licenciatura (ou bacharelado com complementação pedagógica) na mesma área da disciplina que leciona; 2Com formação em bacharelado (sem complementação pedagógica) na mesma área da disciplina que leciona; 3- Com formação superior de licenciatura (ou bacharelado com 
complementação pedagógica) em área diferente daquela que leciona; 4- Com formação superior não considerada na categoria; 5- Sem formação superior.

É importante considerar que ainda há nos anos iniciais e finais do Ensino Fundamental e no Ensino Médio um expressivo percentual de professores atuando sem a devida formação superior, com formação não considerada para a categoria ou com formação em área diferente da que atua.

O MEC, pelo Parecer do CNE $n^{\circ} 22$, de dezembro de 2019, estabelece as Diretrizes Curriculares Nacionais e a Base Nacional Comum Curricular (BNCC) para a Formação Inicial e Continuada de Professores da Educação Básica, à luz das demandas educacionais contemporâneas e das proposições constantes na BNCC, visando tornar efetivas as aprendizagens essenciais que estão previstas nos currículos da Educação Básica.

De acordo com o referido documento, os professores terão que desenvolver um conjunto de competências e habilidades profissionais - conhecimento, prática e engajamento profissional -, que os qualifiquem para uma docência sintonizada com as demandas educacionais de uma sociedade cada vez mais complexa, que exige continuar aprendendo, e cujas características e desafios constam na Agenda 2030 da Organização das Nações Unidas (ONU), com a qual nosso país se comprometeu (MEC, 2019).

Pensar o trabalho do professor exclusivamente como tempo em sala de aula é ignorar a natureza deste trabalho, um erro que nenhuma política pública pode cometer. Assim, a legislação brasileira (LDBEN/1996; LPSN/2008) define a hora-atividade, constituída de momento para o estudo, planejamento e avaliação de temas relevantes ao trabalho docente, tendo como norte o aproveitamento escolar satisfatório. Portanto, as AEC são um espaço para o professor organizar suas aulas, corrigir avaliações, interagir com os pais de alunos e atualizar sua formação cultural e pedagógica (CNE, 2013).

Cabe enfatizar que o trabalho coletivo realizado entre o docente e os gestores escolares, alunos, pais, comunidade, traduz a elaboração de PPP, que sistematiza a organização pedagógica e política da escola. A elaboração de projetos por área do conhecimento ou de forma interdisciplinar, reuniões coletivas de estudo e formação, planejamento conjunto, avaliações qualitativas dos alunos e tarefas similares. $\mathrm{O}$ trabalho coletivo é também traduzido na participação dos docentes nas instâncias de decisão coletiva das escolas, como Conselhos e Colegiados.

As atividades realizadas pelos professores (planejamento, correção de exercícios, provas e similares), chamadas de trabalho elástico e invisível, invadem a vida privada do professor, não tendo visibilidade e nem reconhecimento social. Neste sentido, o trabalho de 
ensinar do professor é um trabalho que se faz o tempo todo em horas remuneradas ou não, e não se sabe onde começa e onde termina (DUARTE, 2011).

\section{As Atividades Extraclasse na Educação Básica: trajetória e dimensão normativa}

No sentido de compreender a fundamentação histórico-educacional brasileira em que se deu a normatização da hora-atividade, em face de prerrogativa de direitos e de princípios constitucionais estabelecidos, a partir dos anos 1970, tradicionais lutas (sindicatos, intelectuais e universidades) foram travadas para uma elevação salarial dos professores de todo o território nacional, fundamentando políticas públicas com centralidade neste profissional.

Com vistas a elucidar o processo da formação de professores destaca-se, sucintamente, o panorama da política educacional brasileira com o crescimento de um movimento crítico que reivindicava mudanças no sistema educacional. Entre suas bandeiras de luta, o movimento defendia a educação pública e gratuita como direito a ser garantido pelo Estado; a erradicação do analfabetismo e a universalização da escola pública (SHIROMA et al., 2011).

Na segunda metade da década de 1970 ganha força um movimento de oposição e de rejeição aos enfoques técnicos e funcionalistas que predominavam naquele momento. De acordo com Candau (1982) a educação passa a ser vista como uma prática social em íntima conexão com o sistema político e econômico vigente.

$\mathrm{Na}$ década de 1980 o Brasil vive um momento de crise e, em meio a um descontentamento generalizado, o debate em relação à formação de professores é intensificado. Por via de consequência, nos anos 1990 o cenário educacional aponta para uma população com pouca qualificação e expressivo percentual de analfabetos e poucos concluintes do ensino médio, com alto índice de evasão escolar naquele momento (SANTOS, 2010).

Para os anos 2000, no país, o destaque fica por conta das críticas ao discurso da formação docente, observando a preocupação com a construção da identidade do educador. É neste contexto, em meio à crise, que a educação brasileira passa a ser agenda de discussão e reestruturação, evidenciando-se como meio capaz de converter a situação e inserir o país no cenário mundial.

Nessa trajetória, compreende-se que a conquista da organização das horas- atividade atribuídas aos professores da Educação Básica é mais uma luta histórica dos educadores 
brasileiros na inter-relação entre organização do currículo, do trabalho pedagógico e das AEC inseridas na jornada de trabalho.

Para tal, em âmbito nacional, a Lei $\mathrm{n}^{\mathrm{o}} 11.738 / 2008$ do Piso Salarial Profissional (PSNP) fixa a composição da jornada de trabalho, estabelecendo no máximo 40 (quarenta) horas semanais, dividida em horas de atividades de docência e horas de AEC (BRASIL, 2008). Esta lei incide sobre os profissionais habilitados em nível superior ou nível médio, na modalidade normal, atuantes nas redes públicas de educação básica da União, dos Estados e dos Municípios; vinculando piso, carreira e jornada (CNE, 2013).

A Lei do Piso define então piso salarial mínimo, indissociado da qualidade da formação e da valorização profissional, compreendendo as condições de trabalho necessárias ao exercício profissional. O eixo da valorização dos profissionais é o grande destaque que deu respaldo às diretrizes políticas regulamentadas pela Lei do Piso Nacional, instituído aos profissionais do magistério público (BRASIL, 2008).

Em âmbito regional, a jornada de trabalho dos professores do magistério público mineiro, antes normatizada pela Lei $n^{0} 15.293 / 2004$, estabelecia jornada de 24 horas semanais, sendo 18 horas no exercício da docência e 6 horas em atividades sem interação com o aluno (MINAS GERAIS, 2004). Por consequência, em 2012, com o ordenamento federal por meio do Parecer no 9/2012 (CNE, 2013), o estado de Minas Gerais ajusta o cumprimento da jornada de trabalho, adequando-se ao estabelecido pela Lei 11.738/2008, a qual instituiu que um terço da jornada de trabalho docente seja destinado às horas de AEC.

O tempo/espaço destinado à formação continuada dos professores do magistério da Educação Básica é conquista histórica de educadores que buscam políticas públicas de valorização do trabalho docente e está aliada à melhoria da qualidade da educação (BRASIL, 2012).

As AEC estabelecidas aos profissionais do magistério público mineiro, conforme a Lei $\mathrm{n}^{\mathrm{o}} 20.592$, de dezembro de 2012, organiza carga horária de 24 (vinte e quatro) horas de jornada de trabalho. Esta carga horária distribui-se em dois terços, 16 horas, no módulo I (docência em sala de aula), e um terço, 8 horas, em módulo II - AEC - para formação em serviço (MINAS GERAIS, 2012).

De acordo como os documentos normativos, especificamente: Lei do PSNP 11.738/2008, Decreto Estadual 46.125/2013 e Ofício Circular GS 2663/2016, as AEC objetivam o crescimento profissional da equipe e o desenvolvimento das ações articuladas e coletivas, visando à implementação do Projeto Político Pedagógico (PPP). Tais legislações caracterizam as AEC como importante instrumento da política pública de formação 
continuada, contribuindo para a melhoria da qualidade do ensino e para o princípio da valorização do magistério. (BRASIL, 2008; MINAS GERAIS, 2013; SEEMG, 2016).

Visam, ainda, ao aperfeiçoamento da prática de sala de aula, fortalecendo a organização e a sistematização do trabalho pedagógico. De modo que o trabalho do professor satisfaça as necessidades básicas de qualidade, produzindo benefícios para aprendizagem e privilegiando a interação e articulação dos professores com o conhecimento teórico/prático (MINAS GERAIS, 2013).

Nesta pesquisa toma-se em especial o Decreto Estadual $n^{0} 46.125 / 2013$ e o Ofício Circular GS no 2663/2016, que formalizam e operacionalizam a prática obrigatória das AEC em MG, atribuindo competências aos gestores institucionais no acompanhamento e monitoramento de sua prática, com vistas a sua efetividade (MINAS GERAIS, 2013; SEEMG, 2016).

Assim, menciona-se que o Ofício Circular GS nº 2663/2016 orienta que das 8 (oito) horas semanais destinadas às AEC, ou seja, nas ações previstas para o momento do módulo II, os professores da educação básica devem: 4h semanais em local de livre escolha do professor e 4h semanais na própria escola ou em local definido pela direção escolar. As horas semanais na própria escola destinam-se:

[...] até 2(duas) horas semanais devem se dedicadas a reuniões de caráter coletivo e as demais deverão se dedicadas a ações de capacitação, formação continuada, planejamento, avaliação e reuniões, bem como outras ações relativas às atribuições específicas do cargo de professores, que não configurem o exercício da docência (SEEMG, 2016).

As horas presenciais destinadas às reuniões de caráter coletivo, programadas entre a direção escolar e o especialista de ensino de Educação Básica (EEB), destinam-se ao desenvolvimento de temas pedagógicos, administrativos ou institucionais, de forma a atender às diretrizes do PPP.

As horas das reuniões com a direção poderão ser acumuladas no decorrer de um mês, podendo ser realizadas fora dos dias e horários de funcionamento da escola, de acordo com o planejamento da direção. A organização das reuniões deverá permitir a participação de todos os profissionais da escola envolvidos no processo pedagógico, como em atividade de conselho de classe e reunião de responsáveis, podendo incluir a participação de pais, alunos e comunidade em geral. 


\section{O caminhar do pesquisador e da pesquisa: trilhas metodológicas}

A condução metodológica que organiza os procedimentos desta pesquisa alicerça-se em etapas que visam à coleta dos dados (seleção e definição das fontes documentais), à exploração do material (análise de conteúdo) e ao tratamento dos resultados (análise e interpretação do conteúdo).

Para tanto, esta pesquisa categoriza-se na área de ciências humanas, com finalidade aplicada e objetivo exploratório. Quanto ao método, a abordagem teórica é a qualitativa, e a técnica para coleta e análise dos dados é a análise de conteúdo. O procedimento técnico para a análise de conteúdo fundamenta-se nas perspectivas de Franco (2005), que faz o seguinte pressuposto:

O ponto de partida da análise de conteúdo é a mensagem, seja ela verbal (oral ou escrita), gestual silenciosa, figurativa, documental ou diretamente provocada. Necessariamente, ela expressa um significado e um sentido. Sentido que não pode ser considerado um ato isolado (FRANCO, 2012, p. 21).

O método e a técnica utilizados levam critérios à resolução do problema, ou seja, as etapas da investigação apresentam como ponto de partida a problemática desta pesquisa, levando naturalmente a uma descoberta. Assim, conduzir-se pela seguinte afirmação: “[...] é pertinente que a pesquisa científica esteja alicerçada pelo método, o que significa elucidar a capacidade de observação, selecionar e organizar cientificamente os caminhos que devem ser percorridos para que a investigação se concretize" (GAIO; CARVALHO; SIMÕES, 2008, p. 148).

Ressalta-se que para este estudo toma-se como análise a prática das AEC, ou seja, as 2 horas coletivas cumpridas na escola ou em outro local definido e autorizado pela direção.

Dessa forma, esta pesquisa foi desenvolvida considerando três etapas norteadoras: na primeira etapa, a seleção e definição das fontes documentais; na segunda o levantamento e a descrição do conteúdo; e na terceira e última etapa a análise e interpretação dos dados. Para garantir o rigor metodológico fez-se necessário realizar os movimentos de delimitar o marco temporal e o universo da pesquisa.

Para este estudo considera-se como recorte temporal o período 2013 a 2018, o qual contempla a implementação das AEC na rede de ensino mineira. Nesse período destacam-se legislações estabelecidas por meio de documentos infrainstitucionais, tendo como propósito a normatização de diretrizes operacionais a serem observadas na rede estadual de ensino. 
A opção pelo recorte encontra-se justificada por meio dos argumentos: o ano de 2013 se constituiu em referencial devido à publicação do Decreto Estadual MG no 46.125, que regulamenta dispositivos da Assembleia Legislativa do Estado de Minas Gerais (MINAS GERAIS, 2013); o ano de 2014 marca a aprovação da Lei 13.005, de 25 de junho de 2014, do Plano Nacional de Educação (PNE), focando as metas 15 - 18 para os eixos da valorização e formação até 2024 (BRASIL, 2014); o ano de 2015 registra o início de uma nova gestão (2015-2018) da política pública educacional em Minas Gerais, dessa vez conduzida pelo Partido dos Trabalhadores (PT), com foco no desenvolvimento de eixos educativos, visando à redução das desigualdades educacionais.

Cabe mencionar que no ano de 2016 leva-se em conta a organização das AEC dos professores do magistério das escolas estaduais de Minas Gerais, normatizada no Ofício Circular G/S SEEMG $n^{\circ}$ 2.663, de 13 de setembro de 2016 (MINAS GERAIS, 2016). Menciona-se, ainda, em maio de 2016 a formalização de parceria entre SEEMG/SRE Diamantina e a Universidade Federal dos Vales do Jequitinhonha e Mucuri (UFVJM), firmando assinatura no Acordo de Cooperação Técnica $n^{0}$ 001/16, fortalecendo articulações interinstitucionais.

O ano de 2017 demarca o ingresso de uma das pesquisadoras no Programa de PósGraduação em Educação (PPGED) e o desenvolvimento do PROEDU VALES, fortalecendo parcerias entre os entes federados, regionais, com vistas à formação continuada no Vale do Jequitinhonha. O ano de 2018 considera a expedição do Ofício Circular GAB/Inspeção Escolar/DIRE, no 03/2018 da SRE Diamantina, que orienta sobre a participação de servidores das escolas da jurisdição em formação continuada. Ainda neste mesmo ano se deu o fechamento dos objetivos da política educacional mineira, 2015-2018.

Por fim, a delimitação temporal deste estudo teve como paramento marcos políticos e pedagógicos que justificam a opção por tratar do objeto de pesquisa no período de 2013 a 2018.

Dada a necessidade de conhecer o contexto em que se insere o público participante, passa-se a estabelecer critérios para sua seleção e organização de informações, salientando características do território em que se dá a pesquisa, a partir de produção de instrumentos para coleta e análise do conteúdo.

Segundo o Plano Mineiro de Desenvolvimento Integrado - 2015 a 2027, administrativamente o território do Vale do Jequitinhonha é composto por 52 municípios organizados nas microrregiões do alto, médio e baixo Jequitinhonha. O presente estudo tem 
como recorte para delimitação do universo o Alto Jequitinhonha, por compreender a microrregião de Diamantina.

Cabe esclarecer que como critério para seleção do público participante (municípios) analisa-se o mapa territorial da área de abrangência da SRE Diamantina. Para tal, toma-se como parâmetro o município sede da SRE, um município representativo do território mais ao sul e outro mais ao norte, utilizando do método de amostragem por conveniência.

Assim, selecionam-se para esta pesquisa os municípios de Diamantina, Serro e Turmalina, respectivamente, dentre os 25 (vinte cinco) municípios mapeados na regional: Alvorada de Minas, Aricanduva, Angelândia, Carbonita, Capelinha, Conceição do Mato Dentro, Congonha dos Norte, Couto Magalhaes de Minas, Datas, Diamantina, Felício dos Santos, Gouveia, Itamarandiba, Leme do Prado, Minas Novas, Monjolos, Presidente Kubitschek, Rio Vermelho, Santo Antônio do Itambé, São Gonçalo do Rio Preto, Senador Modestino Gonçalves, Serra Azul de Minas, Serro, Turmalina, Veredinha.

Para o público participante (escolas) o critério para seleção considerou em cada um dos municípios selecionados a existência de uma (01) escola estadual de Educação Básica com maior número de matrículas efetivas, sobretudo no nível do Ensino Médio. Seleciona-se, respectivamente, os municípios: Diamantina, Serro e Turmalina, e as escolas estaduais EE. Professora Ayna Torres, EE. Ministro Edmundo Lins e EE. Américo Antunes de Oliveira, considerando dados do Sistema Mineiro de Administração Escolar (SIMADE/MG).

Toda a lógica de organização do texto que compõe a análise e discussão encontra-se pautada nos pressupostos metodológicos de Franco (2005), os quais fundamentam a realização de análise de conteúdos.

\section{Panorama da prática das AEC na SER Diamantina - Alto Jequitinhonha: produzindo um diagnóstico regional a partir das categorias de análise}

Neste tópico tomam-se como discussão os resultados obtidos a partir da análise documental sobre a prática das AEC em escolas estaduais da regional Diamantina, Alto Jequitinhonha, cuja interpretação se consolida em três categorias de análise, a saber: Formação Continuada em Serviço, Políticas Públicas para Educação Básica, Elementos Referenciais das AEC: temas e estratégias propostas. 


\section{Categoria formação continuada}

Nesta categoria, têm-se como resultado que a prática coletiva das AEC, na regional Diamantina, é uma das mais importantes estratégias de formação continuada em serviço, sendo espaço para o planejamento, a avaliação e o estudo. Todavia, como pressupõe Pimenta (2002), sugere-se que a prática destas ações promovam atividades que possibilitem aos professores a reflexão sobre a prática pedagógica, assegurando a efetividade do processo de formação.

Com tal perspectiva, essas ações se tornam oportunidade para o compartilhamento de novas metodologias de ensino, para avaliar o processo de ensino e aprendizagem, para o monitoramento das ações pedagógicas planejadas na busca de soluções dos problemas do cotidiano escolar, dentre outras indispensáveis ao trabalho docente.

Pontua-se que no processo do cumprimento das AEC, para os aspectos de acompanhamento e monitoramento pelos gestores previstos no Ofício Circular GS n²663/2016, normalmente, as reuniões são planejadas pela direção escolar em conjunto com o especialista de ensino da Educação Básica, pautando assuntos pertinentes à gestão escolar com vistas ao bom funcionamento administrativo e pedagógico. De modo geral, as reuniões iniciam-se com uma fala da direção referente aos assuntos administrativos e, logo após, é aberto espaço às atividades relacionadas à dimensão pedagógica. Contudo, cabe considerar que o desenvolvimento das ações relevantes ao processo ensino-aprendizagem é executado pelo EEB, pedagogo.

Para evidenciar tais aspectos, seguem trechos de atas analisadas:

A reunião teve início às oito horas com o diretor iniciou a reunião desejando boas vindas a todos e explicando a pauta do dia. Em seguida, passou a palavra para a supervisora [...] que explicou como seria a organização do dia trabalho [...] (Ata Escola I);

Aos dias quatro de fevereiro do referente ano reuniram-se professores, especialistas e direção para discutir e montar o calendário escolar de dois mil e dezesseis; funcionamento pedagógico; estudo de itinerários dos itinerários pedagógicos da educação de Minas Gerais. As reuniões deram início pela diretora [...], pelo estudo da resolução que orienta o calendário escolar [...]. Prosseguindo passamos o funcionamento pedagógico, no que diz respeito à distribuição dos pontos do bimestre e como seriam as avaliações (Ata Escola II);

[...] cada grupo especifico de professores se reuniu com a supervisora para estudo e detalhamento do planejamento pedagógico para o ano letivo (Ata Escola III).

Destaca-se, também, que ao longo do período pesquisado (2013-2018), diferentes equipes (diretores, especialistas de ensino e professores da Educação Básica) constituíram as 
AEC. Nessa observação, pensa-se ser em virtude da rotatividade de servidores motivados pelo processo de efetivação, designação e/ou mudança de lotação presente no cotidiano escolar.

Porém, cabe uma reflexão relativa à mudança nos perfis das equipes de profissionais: a constante alteração no quadro de pessoal pode dificultar o fortalecimento de vínculos e engajamento dos atores envolvidos nas atividades pedagógicas? Ou tais modificações podem dinamizar e/ou renovar a prática profissional?

Quanto aos aspectos da periodicidade do módulo II identifica-se que são realizados encontros semanais ou quinzenais, de acordo com a realidade de cada instituição, flexível conforme as necessidades da equipe, durante todo o ano letivo, considerando cronograma definido entre os participantes durante as reuniões, como se observa em fragmento de atas e relatórios, a seguir:

As reuniões extraclasse (Módulo II) na Escola [...], ocorrem semanalmente (terça-feira) das 17:30 h às 19:30 h e participam das reuniões a Direção, as Especialistas de Educação Básica e os professores do Ensino Fundamental e Médio, dos turnos manhã e tarde (Relatório Escola I);

Sobre a realização do módulo II, horas em reunião, ficou decidido que nossos encontros serão de quatro horas quinzenais no horário de dezessete horas e quarenta minutos até vinte e uma horas e quarenta minutos (Relatório Escola II);

[...] o Módulo II ficou decidido que irá acontecer durante a semana letiva (segunda a quinta-feira) e sempre intercalando para não ser no mesmo dia da semana, e quinzenalmente. Ou seja, quatro horas quinzenais no horário de dezessete horas e quarenta e cinco minutos (Relatório Escola III).

Ainda, identifica-se a participação, em conjunto, da equipe pedagógica, direção, especialistas de ensino e os professores da educação básica, ensino fundamental e médio de todos os turnos. Podem-se realizar também momentos em separado quando de situação específica, como no caso de curso técnico profissional.

Verifica-se, também, nos documentos de registro de frequência de reuniões das AEC (livro de ponto, listas de presença e atas), que em relação à presença do grupo de professor, existe recorrência de ausência por parte de alguns. Estes são identificados, normalmente, com cargo efetivo, o que leva a pensar serem mais resistentes às atividades praticadas no cumprimento do módulo II. Há, ainda, ausência sem justificativa e outras motivadas por diferentes afastamentos: licença de saúde, ajustamento funcional ou justificada por cumprimento dessa carga horária em outra escola.

Assim, discute-se que um dos desafios a serem enfrentados pelos gestores institucionais refere-se à ampliação da participação de alguns professores nas AEC. Refletir se as atividades desenvolvidas se mantêm vinculadas à prática docente, de modo a dissipar o 
desinteresse e a indiferença de tais professores. Alguns desses professores discutem ser dada ênfase aos aspectos técnicos, não se traduzindo em ações significativas para o desenvolvimento profissional.

Pode-se concluir que, de modo geral, na prática das AEC os diretores escolares têm assumido com maior prioridade as questões administrativas e financeiras, os pedagogos assumem a dimensão pedagógica no desenvolvimento dos temas e estratégias planejadas. Há frequência no cumprimento de tarefas, não se percebendo plena efetivação das ações desenvolvidas, de modo que se indica a necessidade de inserção de ações que viabilizem a reflexão sobre as temáticas propostas.

\section{Categoria Políticas Públicas para a Educação Básica}

Esta categoria retoma a normatização das políticas públicas educacionais, relacionando-as ao contexto da implementação das AEC na SRE Diamantina, a partir dos aspectos históricos e legais da política pública de formação de professores do magistério público, sobretudo, em Minas Gerais.

A legislação mineira define que as horas semanais das AEC correspondam a $1 / 3$ do cargo de 24 horas, considerando sua importância para o crescimento profissional da equipe escolar. A prática das AEC visa o desenvolvimento das ações coletivas indispensáveis ao planejamento e à avaliação, na perspectiva da implementação do PPP e da construção de uma escola inclusiva, democrática e participativa, que garanta os direitos de aprendizagem a todos os estudantes (SEEMG/2016).

Cabe discutir que promulgação legal não garante execução. Ou seja, na situação em questão o cumprimento puramente formal das AEC não favorece autorreflexão dos envolvidos. Parte dos professores não incorpora a política das AEC, resistindo em participar das atividades formativas, conforme trecho de relatório Escola III [...]: “o horário extraclasse é um momento privilegiado para a formação de professores e precisam ser usados para esse fim. Porém, o que se vê na prática é uma falta de entendimento desses momentos para tal".

Por consequência, fica comprometida a efetividade das ações, o professor se faz presente para não sofrer consequências, mas sem participação. Evidencia tal realidade um fragmento de relatório da Escola III: “os professores geralmente se apresentam cansados, esgotados de suas tarefas diárias o que poderia ser visto como uma conquista acaba sendo visto como sem proveito". 
Menciona-se que um dos documentos formais que expressam a política pública educacional vigente, na instituição escolar, é o PPP. Segundo guia de orientação para elaboração do PPP, este documento é fundamental para a escola na busca constante por significar/ressignificar sua identidade. Por isso, o envolvimento de toda a comunidade escolar faz-se primordial para que os objetivos sejam alcançados (SEEMG, 2016).

Percebe-se uma diversidade de programas e projetos desenvolvidos no cotidiano escolar. Ainda que as políticas públicas disseminadas pelos programas e projetos visem ao fortalecimento de direitos e valores do cidadão, a discussão fica por conta da pulverização das ações, não consistindo muitas vezes na sistematização das atividades.

Portanto, posiciona-se que o excesso dessas tarefas limita o tempo dos professores na apropriação das propostas e ainda reduz a autonomia da escola no desenvolvimento do que considera mais específico.

\section{Categoria Elementos Referenciais das AEC: temas e estratégias propostas}

Em referenciais legais das AEC orienta-se o estudo, o planejamento e a avaliação como elementos norteadores da formação permanente dos professores. A prática das AEC desenvolve-se a partir de temas e estratégias com abordagem técnico-pedagógica.

Nota-se que há uma ampla variedade de temáticas desenvolvidas como atividades de formação na prática das AEC. Todavia, percebe-se certa fragilidade no quantitativo de temas para o elemento estudo/formação, uma vez que há maior número de temáticas envolvendo os elementos planejamento e avaliação.

Percebem-se, igualmente, nos temas poucas estratégias de estudo/formação que apresentam propostas de intervenção sistemática, aproveitamento escolar, ou seja, atividades que valorizem a metodologia reflexiva. A metodologia aplicada carece de maior efetividade, sugerindo ser estímulo à participação dos professores, devendo considerar a prática da reflexão sobre a ação.

Assim, como resultado dessa categoria, identifica-se que o planejamento e a avaliação são mais desenvolvidos; todavia, o elemento estudo necessita para sua efetividade de maior intervenção institucional. Talvez porque o planejamento e avaliação estão amparados em lei, e o estudo seja mais subjetivo.

Retoma-se que há uma realidade dada, independente da minha reflexão, mas que pode ser captada pela minha reflexão. A ação docente é uma ação complexa que depende da 
eficácia da relação interpessoal e de processos subjetivos como a capacidade de captar a atenção e de criar interesse.

Desse modo, identifica-se que as atividades no geral são mais de caráter técnicoburocrática e menos da ordem do estudo/formação. Em maioria os professores dedicam-se ao trabalho com atividades técnicas imediatistas, como preenchimentos de dados e informações em sistemas, plataformas operacionais.

Os elementos planejamento e avaliação em detrimento do estudo/formação são temas amplamente discutidos na prática do módulo II, necessário, também, à compreensão das ações. Tomando-se como exemplo a ação de avaliação, percebe-se que as metodologias utilizadas para a análise de resultados das avaliações externas não vão além da identificação de dados em escalas, gráficos e tabelas, o que não consolida as mudanças.

\section{Considerações finais}

Conclui-se que a política das AEC como formação em serviço com vistas à melhoria da qualidade da educação ofertada deve ser fortalecida para além de aparato legal obrigatório. As AEC são importantes para o crescimento profissional da equipe e o desenvolvimento de ações coletivas, na perspectiva do PPP. No entanto, alguns professores têm visto as AEC mais como tarefas extras do que oportunidade para o aperfeiçoamento profissional. Em especial, professores não frequentes pensam serem as AEC sobrecarga de suas funções, e não oportunidade para o processo formativo.

Após o exposto, pode-se mencionar que se tem como um dos desafios a lacuna existente na formação do professor, uma vez que a prática aplicada não prioriza a reflexão da prática pedagógica de maneira a relacionar e aprofundar o domínio básico do currículo. Tais discussões levam em conta que as atividades de capacitação docente têm apresentado baixa eficácia porque são desvinculadas da prática, dão excessiva ênfase a aspectos normativos e não traduzem projetos coletivos institucionais. Embora sejam desenvolvidas diversas atividades, elas não se articulam no sentido de promover mudanças na prática profissional.

Com o estudo espera-se contribuir com o diagnóstico produzido, no sentido de auxiliar na ressignificação da prática das atividades extraclasse, fomentando sua efetividade com vistas à melhoria do processo formativo dos professores em serviço nas escolas estaduais da SRE Diamantina, quiçá da SEEMG. 
AGRADECIMENTOS: À SRE Diamantina na pessoa do superintendente, Leonardo Aparecida Soares, por manter um diálogo qualificado entre a educação básica e a universidade, pela constante articulação que resultou na parceria entre a Universidade Federal dos Vales do Jequitinhonha e Mucuri (UFVJM) e a Secretaria Estadual de Educação (SEEMG) através da SRE Diamantina, firmando assinatura no Termo de Cooperação Técnica $n^{\circ} 01 / 2016$.

\section{REFERÊNCIAS}

BRASIL. Constituição (1988). Constituição da República Federativa do Brasil. Brasília, DF: Senado, 1988.

BRASIL. Lei 11.738, de 16 de julho de 2008. Estabelece Piso Salarial Profissional Nacional. Diário Oficial da União: Seção 1, Brasília, DF, p. 1, 17 jul. 2008. PL 7431/2006

BRASIL. Lei 13.005, de 25 de junho de 2014. Aprova o Plano Nacional de Educação - PNE e dá outras providências. Diário Oficial da União: Seção 1, Brasília, DF, p. 1, 26 jun. 2014. PL 8035/2010

BRASIL. Lei 13.415, 16 de fevereiro de 2017. Institui a Reforma do Ensino Médio e dá outras providências. Diário Oficial da União: Seção 1, Brasília, DF, p. 1, 17 fev. 2017. MPV $746 / 2016$

BRASIL. Lei 9.394, de 20 de dezembro de 1996. Estabelece as Diretrizes e Bases da Educação Nacional. Diário Oficial da União: Seção 1, Brasília, DF, p. 27833, 23 dez. 1996. PL 1258/1988

CURY, C. R. J. A educação básica como direito. Cadernos de Pesquisa, Rio de Janeiro, n. 134, p. 293-303, maio/ago. 2008a.

DUARTE, A. Políticas educacionais e o trabalho docente na atualidade: tendências e contradições. In: OLIVEIRA, D. A.; DUARTE, A (Org.). Políticas públicas e educação: regulação e conhecimento. Belo Horizonte: Fino Traço, 2011.

FRANCO, M. L. P. B. Análise de conteúdo. 2. ed. Brasília: Líber Livros, 2005.

GAIO, R.; CARVALHO, R.B.; SIMÕES, R. Métodos e técnicas de pesquisa: a metodologia em questão. In: GAIO, R. (Org.). Metodologia de pesquisa e produção de conhecimento. Petrópolis: Vozes, 2008.

GATTI, B. A. Análise das políticas públicas para formação continuada no Brasil, na última década. Revista Brasileira de Educação, Rio de Janeiro, v. 13, n. 37, p. 57-70, jan./abr. 2008.

HONÓRIO, M. G. et al. As novas diretrizes curriculares nacionais para formação inicial e continuada de professores da educação básica: entre recorrências e novas inquietações. 
RIAEE - Revista Ibero-Americana de Estudos em Educação, v. 12, n. 3, p. 1736-1755, jul./set. 2017. DOI: https://doi.org/10.21723/riaee.v12.n.3.2017.8532

LIBÂNEO, J. C. Pedagogia e pedagogos para quê? São Paulo: Cortez, 2002.

MEC. MINISTÉRIO DA EDUCAÇÃO. Conselho Nacional de Educação. Resolução $\mathrm{CNE} / \mathrm{CP}, \mathrm{n}^{\circ} 02$ de 22 de dezembro de 2017. Institui e orienta a implantação da Base Nacional Comum Curricular. Diário Oficial da União: Seção 1, Brasília, DF, p. 41-44, 22 dez. 2017.

MINAS GERAIS. Assembleia Legislativa do Estado de Minas Gerais. Decreto n. 46.125, de 04 de janeiro de 2013. Regulamenta dispositivos da Lei $\mathrm{n}^{\circ}$ 15.293, de 5 de agosto de 2004. Minas Gerais, Belo Horizonte, 2013. Disponível em:http://www.almg.gov.br/consulte/legislacao/completa/completa.html?tipo=DEC\& num $=46125 \&$ ano $=2013$. Acesso em: 27 out. 2018.

MINAS GERAIS. Assembleia Legislativa. Lei n. 20.592, de 28 de dezembro de 2012. Altera as Leis n 15.293, de 5 de agosto de 2004, que institui as carreiras dos profissionais de Educação Básica do Estado, e 15.301, de 10 de agosto de 2004, que institui as carreiras do Grupo de Atividades de Defesa Social do Poder Executivo, e dá outras providências. Minas Gerais, Belo Horizonte, 2012. Disponível em:http://www.almg.gov.br/consulte/legislacao/completa/completa.html?tipo=LEI\&num=205 $92 \&$ comp $=\& a n o=2012$. Acesso em: 26 out. 2017.

PIMENTA, S. G; GHEDIN, E. Professor reflexivo no Brasil: gênese e crítica de um conceito. 3. ed. São Paulo: Cortez, 2005.

SEEMG. SECRETARIA DO ESTADO DE EDUCAÇÃO DE MINAS GERAIS. Gabinete da Secretaria. Ofício Circular 2663 de 13 de setembro de 2016. Orienta sobre o cumprimento de 1/3 da carga horária do professor destinada as atividades extraclasse. Minas Gerais, Belo Horizonte, 2016. Disponível em:

https://orientaeducacao.files.wordpress.com/2017/02/ofc3adcio-circular-2663-2016cumprimento-de-carga-horc3a1ria-destinada-c3a0s-atividades-extraclasse-4.pdf. Acesso em: 10 jul. 2020.

SERVILHA, M. M. As relações de trocas materiais e simbólicas no mercado municipal de Araçuaí/MG. 2008. 180 f. Dissertação (Mestrado em Instituições sociais e desenvolvimento; Cultura, processos sociais e conhecimento) - Universidade Federal de Viçosa, Viçosa, 2008.

SHIROMA, E. O.; MORAES, M. C. M.; EVANGELISTA, O. Política educacional. 4. ed. Rio de Janeiro: Lamparina, 2011. 


\section{Como referenciar este artigo}

NEVES, E. S. C.; RAMALHO, M. L. Políticas públicas de formação de professores da educação básica: panorama das atividades extraclasse no alto Jequitinhonha/MG. Revista Ibero-Americana de Estudos em Educação, Araraquara, v. 16, n. esp. 2, p. 1179-1198, maio 2021. e-ISSN: 1982-5587. DOI: https://doi.org/10.21723/riaee.v16iesp2.15120

Submissão em: $15 / 12 / 2020$

Revisões requeridas em: 28/01/2021

Aprovado em: 03/03/2021

Publicado em: 01/05/2021 